\title{
UV tolerance and sustained non-photochemical quenching in a desert moss
}

\author{
Jenna T. B. Ekwealor ${ }^{1}$, Theresa Clark ${ }^{2}$, Oliver Dautermann ${ }^{1}$, Alexander Russell ${ }^{2}$, Sotodeh \\ Ebrahimi $^{2}$, Lloyd Stark $^{2}$, Krishna Niyogi ${ }^{1}$, and Brent Mishler ${ }^{1}$ \\ ${ }^{1}$ University of California Berkeley \\ ${ }^{2}$ University of Nevada Las Vegas
}

July 16, 2020

\begin{abstract}
Desert mosses withstand intense sunlight while desiccated and metabolically inactive. We used in situ field experiments to uncover the effects of natural and reduced levels of UV radiation on maximum Photosystem II (PSII) quantum efficiency $(\mathrm{Fv} / \mathrm{Fm})$ and on the relative abundance of photosynthetic pigments and antioxidants in Syntrichia caninervis. We tested the hypothesis that if UV is a stressor, reduction of natural UV levels will result in increased photosynthetic efficiency, but that such reduction will de-harden plants and increase vulnerability to PSII damage with UV exposure. We also measured photosynthetic efficiency over a simulated winter recovery period to assess sustained non-photochemical quenching (NPQ) and its subsequent relaxation. Finally, we measured the effect of UV reduction on photosynthetic pigment and antioxidant abundance. All fieldcollected plants had low Fv/Fm at collection but recovered over eight days in winter conditions. Plants in the low-UV treatment had lower Fv/Fm during recovery than those exposed to natural UV levels and had higher zeaxanthin, lutein, tocopherols, and a higher ratio of chlorophyll a to chlorophyll b. Natural S. caninervis undergoes sustained NPQ that takes days to relax and for efficient photosynthesis to resume. Reduction of UV radiation from sunlight has adverse effects on recovery of Fv/Fm.
\end{abstract}

\section{Acknowledgements}

This work was supported by the University of California, Berkeley, Department of Integrative Biology Graduate Research Fund to JTBE; the UC Natural Reserve System Mildred E. Mathias Research Grant to JTBE; the American Bryological and Lichenological Society Anderson \& Crum Field Research Award to JTBE; German Research Foundation (DFG) project number 427925948 to OD; and National Science Foundation Dimensions of Biodiversity awards (DEB-1638956 and DEB 1638943) to BDM and LRS, respectively. KKN is an investigator of the Howard Hughes Medical Institute. JTBE was also supported by the University of California Berkeley Fellowship, the UC Berkeley Pinto-Fialon Fellowship, and the National Science Foundation Dimensions of Biodiversity award (DEB-1638956).

\section{Introduction}

Desert ecosystems experience extreme daily and seasonal fluctuations in light, temperature, and water availability. Desiccation tolerance, defined as the ability to equilibrate to dry air and resume normal function after rehydration, allows organisms to survive dry periods and limit metabolic activity to periods of moisture availability (Gaff 1977; Proctor et al. 2007; Stark 2017). In the Mojave Desert, summers have both low water availability and intense solar radiation, a challenge for desiccation-tolerant plants such as desert soil mosses. These mosses are quiescent during dry periods and thus are unable to utilize most of the summer radiation for photosynthesis (Stark 2005). Furthermore, while many plants have morphological mechanisms to reduce absorption of excess light, such as altering leaf angle or the production of a waxy cuticle, mosses both lack thick cuticles (Jeffree 2007) and are unable to alter leaf angle once desiccated, although their dry 
state is often a curled state thought to be an adaptation for minimizing light absorption (Zotz \& Kahler 2007).

Fluctuations in light availability can result in absorption of more solar radiation than can be utilized in photosynthesis, resulting in subsequent harm. For example, excess energy absorbed by chlorophylls forms reactive oxygen species (ROS), which react with and damage sensitive molecular machinery (Li, Wakao, Fischer \& Niyogi 2009). Plants face a conundrum, then: while maximizing light absorbance for use in photosynthesis, they must also have adequate photoprotection to avoid damage by excess light, and desert mosses need to be able to balance these requirements both when metabolically active, and when desiccated. One of the major photoprotective mechanisms that plants have is the dissipation of excess light energy as heat, a set of processes collectively known as non-photochemical quenching (NPQ; Müller, Li \& Niyogi 2001; Ruban 2016; Malnoë 2018). Light energy absorbed by chlorophylls can follow one of several competitive pathways: transformation into chemical energy via photochemistry and photosynthetic electron transport, transfer to oxygen to form ROS, re-emission as fluorescence from excited chlorophyll molecules, or dissipation as heat via NPQ. This last pathway of heat dissipation functions like a "safety valve" for photosynthesis (Niyogi 2000) that prevents or reduces damage from excess light.

Plants produce carotenoids, pigments involved in photosynthesis and photoprotection that are typically found in chloroplast membranes (Sunet al. 2018). Carotenoids perform varied functions and many play multiple roles depending on their conformation or location within the chloroplast (Liguori et al. 2017). For example, some carotenoids function both in NPQ and directly quenching ROS such as singlet oxygen (Baroli, Niyogi, Barber \& Heifetz 2000). Additionally, some carotenoids can convert to another type under specific environmental conditions. For instance, under high light conditions violaxanthin is converted to antheraxanthin then zeaxanthin in a reversible process known as the VAZ cycle (Yamamoto, Bugos \& David Hieber 2006; Jahns \& Holzwarth 2012). While these are related and structurally similar molecules, they have different properties and functions in photoprotection. Importantly, a strong correlation between zeaxanthin accumulation and a rapidly inducible form of NPQ, known as energy-dependent quenching (qE; Hortonet al. , 1996; Niyogi, 2000), has been demonstrated in several tracheophyte species (Demmig-Adams 1990; DemmigAdams \& William 1996). Sustained NPQ mechanisms often referred to as photoinhibitory quenching (qI), result in a decrease in the quantum efficiency of photosynthesis and can also be associated with zeaxanthin, though possibly through a different, pH-independent mechanism (Verhoeven, Adams \& Demmig-Adams 1996). Desert plants might be expected to undergo the $\mathrm{qE}$ form of NPQ for diurnal fluctuations in light intensity as well as qI or other sustained NPQ forms, e.g. qH (Malnoë 2018), to deal with seasonal changes in light. Indeed, desiccation-tolerant mosses have been shown to exhibit strong, sustained mechanisms of NPQ (Yamakawa, Fukushima, Itoh \& Heber 2012; Yamakawa \& Itoh 2013).

In addition to changes in overall light intensity, plants, like other organisms, are sensitive to UV radiation. UV is widely considered to be an important stressor that plants must cope with in nature (Jansen, Gaba \& Greenberg 1998; Wolf, Rizzini, Stracke, Ulm \& Rensing 2010). Many sensitive molecules are damaged by absorption of UV-B radiation $(280-315 \mathrm{~nm})$, including components of the photosynthetic apparatus (Teramura \& Sullivan 1994; Jansen et al. 1998). UV-B triggers the production of carotenoids (Middleton \& Teramura 1993), and some of the same high-light photoprotective mechanisms can also protect plants from UV radiation. For example, it was demonstrated that zeaxanthin contributes to UV stress protection and damage prevention in tobacco (Götz, Sandmann \& Römer 2002). Additionally, some plants have evolved novel UV-absorbing chemical sunscreens to reduce the amount of UV reaching sensitive molecules.

Exposure to UV radiation may not always be stressful for photosynthetic organisms, however. Recent studies of ecologically relevant levels of UV radiation have shown that UV exposure may induce regulatory processes and may even be beneficial (Rozema, Van De Staaij, Björn \& Caldwell 1997; Frohnmeyer \& Staiger 2003; Ulm \& Nagy 2005; Davey et al.2012; Morales et al. 2013; Singh, Agrawal \& Agrawal 2014). For example, UVR8, the UV-B receptor in plants, mediates the accumulation of transcripts encoding early light-inducible proteins (ELIPs) (Singhet al. 2014), which function in photoprotection (Hutin et al. 2003). Commonly, low doses of UV radiation can induce protective responses that affect the plant's tolerance to various other abiotic and 
biotic stresses (Frohnmeyer \& Staiger 2003). For instance, ELIPs are also important for desiccation tolerance in resurrection plants (Zeng 2002; Oliver, Dowd, Zaragoza, Mauget \& Payton 2004; Van Buren, Pardo, Wai, Evans \& Bartels 2019).

Studies on UV protection in mosses have been limited. Much of the research on this topic has been on Antarctic mosses and often involves UV-B supplementation in greenhouses or growth chambers (Searles, Flint \& Caldwell 2001; Gwynn-Jones et al. 1999; Searles et al.1999; Lud, Moerdijk, Van de Poll, Buma \& Huiskes 2002; Martínez-Abaigaret al. 2003; Newsham 2003; Green, Kulle, Pannewitz, Sancho \& Schroeter 2005; Núñez-Olivera, Arróniz-Crespo, Martínez-Abaigar, Tomás \& Beaucourt 2005; Robinson, Turnbull \& Lovelock 2005; Dunn \& Robinson 2006; Björn 2007; Turnbull, Leslie \& Robinson 2009). Thus, there is a need for a better understanding of the effects of natural levels of UV radiation in a field setting. Nearly all mosses tested in nature appear to be minimally damaged by ambient UV levels, but some are sensitive to it (Boelen, De Boer, De Bakker \& Rozema 2006). Furthermore, in some species UV protection appears to be physiologically constitutive while in others it is plastic. For example, the mosses Ceratodon purpureus and Bryum subrotundifolium exhibit sun forms that are tolerant to UV and shade forms that are not but can be acclimated to UV within a week in natural sunlight (Green et al. 2005). On the other hand, in the Antarctic mosses Sanionia uncinata, Chorisodontium aciphyllum, Warnstorfia sarmentosa, andPolytrichum strictum , UV-B absorbing compounds are not induced by enhanced UV-B radiation (Boelen et al. 2006). Similarly,Syntrichia ruralis, a dryland moss closely related to $S$. caninervis, was unaffected by UV-B radiation, based on chlorophyll fluorescence (Takács et al. 1999; Csintalan, Tuba, Takács \& Laitat 2001). Studies have shown that UV tolerance correlates with desiccation tolerance (Takács et al. 1999), and that desiccation itself confers extra protection from UV in two Antarctic mosses (Turnbull et al. 2009). Both habitat and genetics are strong predictors of UV tolerance in bryophytes but there is a lot of within- and among-genera variability (Hespanhol, Fabón, Monforte, Martínez-Abaigar \& Núñez-Olivera 2014). Thus, the need to study each species in its own environment is critical to understanding how UV is tolerated in nature.

The desert moss Syntrichia caninervis is a highly desiccation-tolerant (Proctor et al. 2007; Stark 2017) important member of western North American dryland biological soil crust communities, including in the Mojave Desert (Stark, Mishler \& McLetchie 1998; Bowker, Stark, McLetchie \& Mishler 2000; Coe, Belnap \& Sparks 2012; Antoninka, Bowker, Reed \& Doherty 2016; Seppelt, Downing, Deane-Coe, Zhang \& Zhang 2016). This species frequently forms continuous or semi-continuous carpets in exposed, intershrub desert soil crusts and tolerates high levels of solar radiation while dry. Interestingly, mature shoots of $S$. caninervis develop a dark brown or black coloration in nature but remain bright green when grown in dim, artificial laboratory light (personal observation), suggesting a plastic pigment-accumulation reaction in response to light exposure. Accumulation of dark pigmentation varies in nature, too. S. caninervis plants are greener in very low-light microhabitats (Ekwealor \& Fisher 2020) and when UV is filtered out (Ekwealor, in press). This apparent "suntan" pattern suggests the possibility of an adaptive response for UV protection, though that function has not yet been tested in S. caninervis .

In this study the effects of natural and reduced levels of UV radiation on Photosystem II (PSII) quantum efficiency and the relative abundance of photosynthetic pigments and antioxidants were evaluated in $S$. caninervis. We used a year-long manipulative field experiment to test the hypothesis that if UV radiation is a stressor then a reduction of natural levels of UV will result in increased maximum PSII quantum efficiency $\left(F_{\mathrm{v}} / F_{\mathrm{m}}\right)$ but will de-harden plants and thus increase vulnerability to UV damage at PSII. We also measured abundance of photosynthetic pigments and antioxidants as well as $F_{\mathrm{v}} / F_{\mathrm{m}}$ over a simulated winter recovery period to assess sustained NPQ and its subsequent relaxation. This study aimed to understand the effects of natural levels of solar radiation on photosynthesis, to reveal how these plants are able to survive extended periods of desiccated quiescence in their desert habitat.

\section{Materials and Methods}

Study site and sampling

The study was conducted in the southwestern Mojave Desert at the Sweeney Granite Mountains Desert 
Research Center, an ecological reserve of the University of California Natural Reserve System. Experimental treatments and sampling took place within a cove in the Granite Mountains (ca. $1360 \mathrm{~m}$ elevation) dominated by Cylindropuntia acanthocarpa, C. echinocarpa, Larrea tridendata, and Yucca schidigera (34.7849 ${ }^{\circ}$ $\left.\mathrm{N}, 115.6620^{\circ} \mathrm{W}\right)$. The terrain in this area is relatively flat with some gentle slopes and is characterized by abundant large granitic boulders and seasonal washes. The climate is arid with a mean annual precipitation of $217 \mathrm{~mm}$, a mean summer (May through October) daily high temperature of $29{ }^{\circ} \mathrm{C}$, a mean summer daily low temperature of $18{ }^{\circ} \mathrm{C}$, a mean winter (November through April) daily high temperature of $16{ }^{\circ} \mathrm{C}$, and a mean winter daily low temperature of $6{ }^{\circ} \mathrm{C}$ (data from UC Sweeney Granite Mountains Desert Research Center, Sweeney Granite Reserve Weather Station, RGSC1, 34.78 N, 115.65 W, $1304 \mathrm{~m}$ elevation).

In June 2018, twenty $12.7 \mathrm{~cm} \times 12.7 \mathrm{~cm}(5 " \times 5$ ") UV-filtering windows (Figure S1), $3.175 \mathrm{~mm}(1 / 8 \mathrm{in})$ thick (OP-3 acrylic, Acrylite, Sanford, ME, USA), were installed over target Syntrichia caninerviscushions at the study site (a voucher specimen, Ekwealor 015, has been deposited in the UC herbarium). The UV-filtering windows filter wavelengths $400 \mathrm{~nm}$ and smaller, transmitting only $1 \%$ of UV-B radiation. In a paired design, twenty UV-transmitting, but otherwise identical acrylic windows (Polycast Solacryl SUVT acrylic, Spartech, Maryland Heights, MO, USA) were placed over target cushions located within $1 \mathrm{~m}$ of their UV-filtering counterpart. These UV-transmitting windows transmit at least $85 \%$ of UV-B radiation, and both transmit $90 \%$ of photosynthetically active radiation ( $400-700 \mathrm{~nm}$; PAR). Additionally, three pairs of windows were installed for microclimate measurements (see below). All windows were installed using 8-32 threaded nylon legs so that each window was nearly flush with the ground on the south edge and approximately $2.5 \mathrm{~cm}$ off the ground on the north edge, creating a ca. $13^{\circ}$ angle with the soil surface (Figure 1a).

Window installations were monitored and re-secured monthly until sample collection in June 2019. At that time, one UV-filtering window had been lost to weather and that pair was excluded from downstream analyses. Cushions were collected using $9 \mathrm{~cm}$ diameter culture dishes from each of the remaining 19 pair; furthermore an additional third, un-manipulated reference sample was collected from each of the 19 microsites (within $1 \mathrm{~m}$ of the window pair) to test for effects of a window treatment per se. Specimens were stored dry (Figure 1b) and in the dark until analyses.

\section{Light Measurements}

PAR and UV-A/B radiation $(250-400 \mathrm{~nm})$ were measured under windows and at nearby un-manipulated site reference mosses in April 2019 using LightScout UV and Quantum Sensors and the LightScout Sensor Reader (Spectrum Technologies, Aurora, IL, USA). Data were first tested for normality with the ShapiroWilk test (Shapiro \& Wilk 1965). Differences in PAR between field treatments were tested for with two-tailed paired Student's T-tests and differences in UV were tested for with Wilcoxon signed-rank tests (Wilcoxon 1945). Significance was adjusted with the Benjamini and Hochberg correction (Benjamini \& Hochberg 1995) to account for the false discovery rate of multiple tests (Jafari \& Ansari-Pour 2019).

\section{Microclimate}

In order to understand the effects of the window treatments on the microclimate, data loggers were deployed under three pairs of windows and at nearby soil-surface mosses. These windows were installed specifically for this purpose and moss samples were not collected from them. To log temperature and relative humidity $(\mathrm{RH})$ every five minutes, iButton hygrochrons (Maxim Integrated, San Jose, CA, USA) were deployed in winter (February) and summer (September) 2019 for a period of four and two days, respectively. In addition to the three pairs, in September iButton hygrochrons were used to measure temperature and $\mathrm{RH}$ of a nearby (within $1 \mathrm{~m}$ of windows) un-manipulated site reference moss cushion.

Temperature and RH data were summarized to mean daily high and low per site per treatment (UV-filtered, UV-transmitted, plus site reference for September), tested for normality with the Shapiro-Wilk test (Shapiro \& Wilk 1965), and subsequently tested for significance of treatment effect with one ANOVA for each data set (summer and winter). Significance was adjusted with the Benjamini and Hochberg method (Benjamini \& Hochberg 1995). 


\section{Laboratory cultures}

Shoots from a previously isolated clone of a $S$. caninervisherbarium specimen from southern Nevada, U.S.A. (Stark NV-107,USA, Nevada, Clark County, Newberry Mts, Christmas Tree Pass; UNLV) were cultivated in a growth chamber set to an 18 -hour photoperiod $\left(18{ }^{\circ} \mathrm{C}\right.$ light, $12{ }^{\circ} \mathrm{C}$ dark $)$, at $\sim 30 \mu \mathrm{mol} \mathrm{m}^{-2} \mathrm{~s}^{-1} \mathrm{PAR}$ in order to compare pigment and antioxidant profiles of field and laboratory-grown plants. Cultures of a single genotype were grown from fragments on $1.2 \%$ agar made with an inorganic nutrient solution (Hoagland \& Arnon 1950).

\section{Chlorophyll fluorescence of field-manipulated samples}

In order to measure maximum PSII quantum efficiency $\left(F_{\mathrm{v}} / F_{\mathrm{m}}\right)$ and actual PSII quantum efficiency (ФPSII), chlorophyll fluorescence was carried out according to a modified version of the protocol in (Clark 2020). Ten to fifteen shoots of each specimen were sampled by selecting shoots randomly from each cushion, when multiple cushions present. Shoots were hydrated and quickly assembled into Hansatech FMS/LC darkadaptation leaf clips (Hansatech Instruments, Norfolk, UK) that were modified to have a deeper cavity to allow tall moss shoots to stand upright on a small, circular piece of filter paper created with a hole-punch. This system allows the entire moss "bouquet" to be easily removed by grabbing the filter paper with forceps, so that the same shoots could be confidently measured at different time points.

Immediately after assembly of shoots in the clip, it was then closed to allow the moss shoots to acclimate to darkness (allow PSII reaction centers to open fully) for 30 minutes. At precisely 30 minutes, the clip was placed into the Hansatech Pulse-Modulated chlorophyll fluorescence measurement system (FMS) 2 (Hansatech Instruments, Norfolk, UK), the clip was opened, and the script was run with actinic light of photosynthetic flux density of $150 \mu \mathrm{mol}$ photons $\mathrm{m}^{-2} \mathrm{~s}^{-1}$ for $200 \mathrm{~s}$ and a saturation pulse of $3000 \mu \mathrm{mol}$ photons $\mathrm{m}^{-2} \mathrm{~s}^{-1}$ for $0.8 \mathrm{~s}$ before and after the actinic light. Following the initial fluorometry time point $(0$ hours; $\mathrm{T}_{0}$ ), samples were placed into "water thrones" as described in (Clark 2020). Water thrones are part of a system that allows mosses to remain hydrated and near $100 \% \mathrm{RH}$ through the water wicking in a chemical laboratory wipe. The samples were placed in a Percival E30B growth chamber (Percival Scientific, Perry, Iowa, USA) under simulated winter recovery conditions consisting of a 10 hour photoperiod $\left(12{ }^{\circ} \mathrm{C}\right.$ light, 5 ${ }^{\circ} \mathrm{C}$ dark) with $70-85 \% \mathrm{RH}$ in chamber at $150 \mu \mathrm{mol} \mathrm{m} \mathrm{m}^{-2} \mathrm{~s}^{-1}$ where temperature and RH were monitored with an iButton data logger (Maxim Integrated, San Jose, CA, USA).

After 24 hours in recovery, samples were again placed into the fluorometer clips, closed to allow PSII to dark acclimate, and run through the fluorometer script for a second time point $\left(24\right.$ hours; $\left.\mathrm{T}_{24}\right)$. Following this round, samples were again transferred to simulated winter recovery conditions in the growth chamber water thrones until the next time point. Finally, fluorometer measurements were repeated once more at 192 hours (eight days; $\left.\mathrm{T}_{192}\right)$.

Fluorescence data were first tested for normality with the Shapiro-Wilk test (Shapiro \& Wilk 1965) and subsequently all $F_{\mathrm{v}} / F_{\mathrm{m}}$ and $\Phi$ PSII were compared pairwise using Wilcoxon signed-rank tests (Wilcoxon 1945) at each time point. Significance was then adjusted for multiple-testing with the Benjamini and Hochberg method (Benjamini \& Hochberg 1995).

\section{Test for Photosystem II protection from UV radiation}

At the same time that stems from the field were measured as in the previous section, 10-15 additional shoots per sample were selected from field-collected samples as above and given a UV radiation treatment in the laboratory. Samples were kept dry and placed under four T8 reptile bulbs (ReptiSun 10.0 UVB, Zoo Med Laboratories Inc., San Luis Obispo, CA, USA) in culture dishes covered by UV-transmitting acrylic in order to filter out UV-C wavelengths, which in nature are absorbed by earth's atmosphere. Lamps were placed $2.5 \mathrm{~cm}$ from specimens for a UV-A/B flux rate of $80 \mu \mathrm{mol} \mathrm{m} \mathrm{m}^{-2} \mathrm{~s}^{-1}$ and $160 \mu \mathrm{mol} \mathrm{m}^{-2} \mathrm{~s}^{-1} \mathrm{PAR}$ for 14 hours (rotated once during treatment). After the UV treatment, shoots were prepared for chlorophyll fluorescence identically as above. A fan was placed to circulate under the lamp and temperature and RH were monitored with an iButton data logger (Maxim Integrated, San Jose, CA, USA; $26{ }^{\circ} \mathrm{C}$ mean temperature, $19 \%$ mean 
$\mathrm{RH})$.

Fluorescence data were gathered and analyzed as above with the Shapiro-Wilk test (Shapiro \& Wilk 1965) for normality and pairwise Wilcoxon signed-rank tests for $F_{\mathrm{v}} / F_{\mathrm{m}}$ and $\Phi$ PSII (Wilcoxon 1945). Additionally, to test the effects of the laboratory UV treatment, Wilcoxon signed-rank tests were performed on $F_{\mathrm{v}} / F_{\mathrm{m}}$ and $\Phi$ PSII across laboratory treatments (with or without additional laboratory UV) within each treatment group at each time point of recovery $\left(\mathrm{T}_{0}, \mathrm{~T}_{24}\right.$, and $\left.\mathrm{T}_{192}\right)$. Significance was adjusted for multiple-testing with the Benjamini and Hochberg method (Benjamini \& Hochberg 1995).

Photosynthesis pigment and tocopherol content

Pigment and tocopherol content was quantified by high performance liquid chromatography (HPLC) in at least triplicate. Approximately $5 \mathrm{mg}$ (about five shoots) of dry, soil-free plant material was collected from each experimental field sample at the end of the one-year study and homogenized in $100 \%$ acetone using a FastPrep-24 5G bead beater (MP Biomedicals, Irvine, CA, USA). Additionally, 5-10 shoots of lab cultured $S$. caninervis were prepared in at least triplicate. Samples were then centrifuged at 14,000 g for $30 \mathrm{~s}$. Supernatants were passed through a $0.45 \mu \mathrm{m}$ nylon filter (part F2504-1, Thermo Fisher Scientific, Waltham, MA, USA) prior to injection of $25 \mu \mathrm{L}$ onto a ProntoSIL 200-5-C30, $5.0 \mu \mathrm{m}, 250 \mathrm{~mm} \times 4.6 \mathrm{~mm}$ column equipped with a ProntoSIL 200-5-C30, $5.0 \mu \mathrm{m}, 20 \mathrm{~mm} \times 4.0 \mathrm{~mm}$ guard column (Bischoff Analysetechnik, Leonberg, Germany) following the HPLC method and gradient conditions of Dautermann et al. (2020). Replicates of resulting pigments quantities were normalized to total pigment content and tocopherols were normalized to total chlorophyll content. All 186 replicates were screened for outliers using Cook's distance threshold of eight (Cook 1977; Kim \& Storer 1996). Fifteen replicates were eliminated from downstream analyses as outliers. Variation in pigment and antioxidant relative abundances in all field and laboratory replicates was reduced to two dimensions with a principal components analysis. Data were then tested for normality with the Shapiro-Wilk test (Shapiro \& Wilk 1965). Subsequently, field-collected site reference plants and laboratory cultured plants were compared using the mean of replicates in an unpaired Wilcoxon rank-sum test (Mann \& Whitney 1947) and field treatments were compared using the mean of replicates in paired Wilcoxon signed-rank tests (Wilcoxon 1945). Significance was adjusted with the Benjamini and Hochberg method (Benjamini \& Hochberg 1995; Jafari \& Ansari-Pour 2019).

\section{Results}

\section{Light Measurements}

PAR was measured in each field treatment to assess to what extent it is affected by the windows. There was no significant difference in PAR between UV-filtering and UV-transmitting windows. The mean PAR in UV-filtered plots was $1324 \mu \mathrm{mol} \mathrm{m} \mathrm{m}^{-2}$ and the mean in UV-transmitted plots was $1343 \mu \mathrm{mol} \mathrm{m} \mathrm{m} \mathrm{s}^{-1}$. PAR in site reference plots (mean $=1472 \mu \mathrm{mol} \mathrm{m} \mathrm{m}^{-2} \mathrm{~s}^{-1}$ ) was slightly but significantly higher than both UV-filtered and UV-transmitted windows $(P=0.0002$ and $P=0.006$, respectively). UV was significantly lower under UV-filtering windows relative to UV-transmitting windows (approximately $98 \%$ reduction from 91.3 to 1.7 $\left.\mu \mathrm{mol} \mathrm{m} \mathrm{m}^{-2} \mathrm{~s}^{-1} ; P<0.0001\right)$. Site reference sites had higher UV than both UV-filtered and UV-transmitted sites (mean $=105 \mu \mathrm{mol} \mathrm{m} \mathrm{m}^{-2} \mathrm{~s}^{-1} ; P<0.0001$ and $P=0.001$, respectively).

\section{Microclimate}

Temperature and relative humidity were measured in winter and summer in order to test for the effects of UV-filtering and UV-transmitting windows on microclimate. Neither the winter mean daily low temperature nor the mean daily high temperature significantly differed between the UV-filtering and UV-transmitting windows (Table 1). Similarly, the winter mean daily low RH did not differ significantly between the two window treatments (Table 1). However, mean daily high RH was significantly higher under UV-filtering windows (Table 1).

Summer microclimate monitoring included both treatment windows as well as nearby, un-manipulated site reference measurements. There was no significant difference in mean daily low temperatures or mean daily high temperatures among the two treatment windows or site reference plots (Table 1). Summer mean daily 
high RH was higher in the site reference plot (Table 1), although there were no significant differences across any of the treatment groups. Field treatment did, however, have a significant effect on mean daily low RH (highest in site reference plots; $P=0.032$, Table 1).

\section{Chlorophyll fluorescence of field-manipulated samples}

$F_{\mathrm{v}} / F_{\mathrm{m}}$ and $\Phi$ PSII were measured at three time points over a simulated winter recovery period (192 hours) to assess photosynthetic efficiency. At $\mathrm{T}_{0}$, desiccated samples from all three field treatment groups had very low $F_{\mathrm{v}} / F \mathrm{~m}$ values (mean $\mathrm{UV}$-filtered $=0.044$, mean $\mathrm{UV}$-transmitted $=0.049$, and mean site reference $=0.108$ ). There was no statistical difference in $F_{\mathrm{v}} / F_{\mathrm{m}}$ between any groups at $\mathrm{T}_{0}$ (Figure 2). After 24 hours in simulated winter recovery conditions, $F_{\mathrm{v}} / F_{\mathrm{m}}$ had increased in all samples. At $\mathrm{T}_{24}, F_{\mathrm{v}} / F_{\mathrm{m}}$ of samples from UV-transmitting windows were significantly higher than those from UV-filtering windows (mean UV-filtered $=0.532$, mean UV-transmitted $=0.599)$. Site reference samples had significantly higher $F$ $\mathrm{v} / F_{\mathrm{m}}$ values $($ mean $=0.631)$ than $\mathrm{UV}$-transmitted samples. At $\mathrm{T}_{192}, F_{\mathrm{v}} / F_{\mathrm{m}}$ values of all treatments were also significantly different from each other in the same rank order: UV-transmitted were higher than UV-filtered, and site reference samples were higher than UV-transmitted; (mean UV-filtered $=0.790$, mean $\mathrm{UV}$-transmitted $=0.812$, and mean site reference $=0.839$ ). All treatment groups had relatively constant $F$ o (relative to $F \mathrm{~m}$ ) over the simulated winter recovery period while $F$ m increased from near 100 to at least 700 bits (Figure S4).

The pattern of $\Phi$ PSII measured at $150 \mu \mathrm{mol}$ photons $\mathrm{m}^{-2} \mathrm{~s}^{-1}$ over the recovery period was similar to that of $F_{\mathrm{v}} / F_{\mathrm{m}}$. There was no statistical difference in $\Phi$ PSII between UV-filtered samples and UV-transmitted samples at $\mathrm{T}_{0}$ nor between $\Phi P S I I$ values of site reference plants and UV-transmitted plants (Table 2). After 24 hours in recovery, $\Phi$ PSII of all samples had increased. $\Phi$ PSII of samples from UV-transmitting windows were significantly higher than those from UV-filtering windows. Site reference mean $\Phi$ PSII was 0.425, and there was no significant difference between site reference and UV-transmitted samples. At $\mathrm{T}_{192}$, neither UV-filtering and UV-transmitting, nor UV-transmitting and site reference $\Phi P S I I$ values were significantly different from one another (site reference mean $=0.630$ ).

\section{Test for Photosystem II protection from UV radiation}

To test the hypothesis that UV filtering would increase vulnerability to UV damage at PSII, desiccated samples were also subjected to a laboratory UV treatment, and $\mathrm{F}_{\mathrm{v}} / \mathrm{F}_{\mathrm{m}}$ and SPSII were measured during simulated winter recovery conditions. There were no significant differences in $F_{\mathrm{v}} / F_{\mathrm{m}}$ within each treatment group (UV-filtered, UV-transmitted, and site reference) at $\mathrm{T}_{0}$ and $\mathrm{T}_{192}$ after the laboratory $\mathrm{UV}$ treatment (Figure $\mathrm{S} 2$ ). At $\mathrm{T}_{24}, \mathrm{UV}$-transmitted field plants that received a laboratory UV treatment had significantly higher $F_{\mathrm{v}} / F_{\mathrm{m}}$ than UV-transmitted that did not. Similarly, QPSII of each treatment group was not significantly different after the laboratory UV treatment at $\mathrm{T}_{0}$ and $\mathrm{T}_{192}$, but at $\mathrm{T}_{24}$ was significantly higher in laboratory UV-treated UV-transmitted samples than UV-transmitted with no laboratory UV treatment (Figure S3).

\section{Photosynthesis pigment and antioxidant content}

Photosynthesis pigments and antioxidants were measured on field collected plants from all treatments. Zeaxanthin, lutein, and the chlorophyll $a: b$ levels increased with UV-filtering (Figure 3). Site reference samples also had significantly more zeaxanthin, lutein, $\beta$ - carotene, and a higher chlorophyll $a: b$ than UV-transmitted samples. There was no significant difference in neoxanthin, violaxanthin, antheraxanthin, $\beta$ - carotene, chlorophyll $a$, or chlorophyll $b$ between UV-filtered samples and UV-transmitted samples.

The three field treatment groups (UV-filtered, UV-transmitted, and site reference) and the laboratory cultures separated along PCA axis PC1, which explained $39.9 \%$ of the variation (Figure 4). The field treatments were largely overlapping with each other, and the laboratory cultures were relatively distant. Site reference plants had less chlorophyll $b$, violaxanthin, and neoxanthin than lab cultured plants (Table 3). These fieldcollected plants also had more zeaxanthin, lutein, and $\beta$-carotene than lab cultured plants (Table 3). There was no significant difference in antheraxanthin or chlorophyll $a$ abundance between site reference and lab 
cultured plants.

Normalized $\alpha$ - and $\beta$-tocopherols increased with removal of UV (Table 4 ). Site reference samples had higher $\alpha$ and $\beta$-tocopherols than UV-transmitted samples (Figure 5). Field-collected plants had much higher relative abundance of $\alpha$ - and $\beta$-tocopherols than lab cultured plants (Table 5).

\section{Discussion}

$F_{v} / F_{m}$ recovery in winter conditions

Desiccated, field-collected $S$. caninervis plants from all treatments had very low maximum potential PSII quantum efficiency, $F_{\mathrm{v}} / F_{\mathrm{m}}$, when initially rehydrated but recovered over eight days in simulated winter conditions. In healthy land plants $F_{\mathrm{v}} / F_{\mathrm{m}}$ is nearly constant around 0.83 (Björkman \& Demmig 1987; Proctor 2001), and over the eight-day recovery period the $F_{\mathrm{v}} / F_{\mathrm{m}}$ increased from less than 0.1 to 0.81 . Often a low $F_{\mathrm{v}} / F_{\mathrm{m}}$ is interpreted as indicative of stress related to PSII damage (Demmig \& Björkman 1987; Csintalan, Proctor \& Tuba 1999), and thus its increase is interpreted as repair of PSII. However, because $F_{\mathrm{v}} / F_{\mathrm{m}}$ is a normalized ratio it is important to understand which component is driving the change. As $F_{\mathrm{v}}=F_{\mathrm{m}}-F_{\mathrm{o}}, F_{\mathrm{v}} / F_{\mathrm{m}}$ is equivalent to $\left(F_{\mathrm{m}}-F_{\mathrm{o}}\right) / F_{\mathrm{m}}$, meaning that $F_{\mathrm{v}} / F_{\mathrm{m}}$ can increase due to an increase in $F$ m or a decrease in $F$ o, or both, thus understanding underlying change in these variables can provide insight on the underlying biological processes. For example, $F_{\mathrm{o}}$ is high, relative to $F \mathrm{~m}$, when PSII is damaged (Ritchie 2006; Murchie \& Lawson 2013). An increase in $F_{\mathrm{v}} / F_{\mathrm{m}}$ due to a decrease in $F$ o with a relatively constant $F \mathrm{~m}$ would be strongly indicative of PSII damage and subsequent repair. On the other hand, an increase in $F_{\mathrm{v}} / F_{\mathrm{m}}$ driven by an increase in $F_{\mathrm{m}}$ is consistent with a relaxation of NPQ (Müller et al. 2001). This latter scenario is what we observed here: an increase in $F_{\mathrm{v}} / F_{\mathrm{m}}$ over the recovery period driven by $F \mathrm{~m}$, and indicative of relaxation of sustained NPQ rather than repair of damaged PSII (Figure S4).

\section{Different pigment and antioxidant profiles in field-collected and lab-cultured plants}

Comparison of the photosynthetic pigment profiles in field-collected and lab-cultured S. caninervis supports this hypothesis of relaxation of sustained NPQ. Zeaxanthin, which is associated with both rapidly reversible (qE) and sustained NPQ mechanisms such as photoinhibitory quenching (qI; Demmig-Adams, 1990; Verhoeven et al. , 1996), was more than five times higher in field-collected plants than in lab-cultured plants (Table 3). In fact, the relative VAZ pool was larger in field-collected plants, which is unsurprising as these pigments increase in abundance in high-light environments (Siefermann-Harms 1985; Demmig-Adams 1990; Jahns, Latowski \& Strzalka 2009). Similarly, the total chlorophyll pool was reduced and the ratio of chlorophyll $a$ $: b$ was increased in field-collected plants, also consistent with acclimation to high light intensity (Björkman 1981; Leong \& Anderson 1984; Lindahl, Yang \& Andersson 1995). Tocopherol abundance was much higher in field-collected plants than those cultured in the lab, as well (Table 5). Tocopherols are membrane-bound antioxidants that may be increased due to the higher light intensity and UV exposure in the field site (Delong \& Steffen 1998; Yao et al.2015) or due to other stresses such as desiccation and freezing that these plants frequently face in their natural habitat (Munné-Bosch 2005).

\section{Altered $F_{v} / F_{m}$ recovery following $U V$-filtering}

Surprisingly, $F_{\mathrm{v}} / F_{\mathrm{m}}$ was not affected in desiccated $S$. caninervis when natural levels of UV were reduced, but the recovery of $F_{\mathrm{v}} / F_{\mathrm{m}}$ was impaired during at least 192 hours in winter recovery conditions (Figure 2). In contrast, many plants respond to supplemental UV radiation with reduced $F_{\mathrm{v}} / F_{\mathrm{m}}$ (Bradshaw, 1965; Strid et al. , 1990; He et al. , 1993; Pukacki \& Modrzyński, 1998; Ranjbarfordoei et al. , 2011; but see Takácset al. , 1999; Csintalan et al. , 2001; Lau et al. , 2006; Basahi et al. , 2014). Furthermore, relative abundance of the xanthophylls zeaxanthin and lutein was also increased in UV-filtered plants (Figure 3), a response also typically seen with UV supplementation (Agrawal, Singh \& Agrawal 2009). Why should removal of UV radiation, presumably a stressor, result in altered recovery of $F_{\mathrm{v}} / F_{\mathrm{m}}$ and more antioxidant xanthophylls in $S$. caninervis ? One possible explanation for the observed defect in $F{ }_{\mathrm{v}} / F_{\mathrm{m}}$ recovery is that removal of UV somehow causes an impairment in relaxation of sustained NPQ. As with un-manipulated field-collected 
plants, the observed $F_{\mathrm{v}} / F_{\mathrm{m}}$ increase over the recovery period for UV-filtered and UV-transmitted plants was driven by an increase in $F \mathrm{~m}$ and thus is consistent with relaxation of sustained NPQ. Indeed, the increased abundance of zeaxanthin with removal of UV is consistent with the hypothesis that UV filtering induces a sustained zeaxanthin-related NPQ (Verhoeven et al. 1996).

It is possible that UV radiation is a photomorphogenic (Gitz \& Liu-Gitz 2003) or regulatory signal rather than (or in addition to) being a stressor and the absence of this signal affects NPQ recovery. For example, UV may induce production of enzymatic antioxidants or phenolics (Cooper-Driver, Bhattacharya \& Harborne 1998; Clarke \& Robinson 2008; Waterman et al. 2017) that may have roles beyond UV protection, such as in desiccation tolerance (Gitz \& Liu-Gitz 2003; Poulson, Boeger \& Donahue 2006; Robson, Hartikainen \& Aphalo 2015). Without these protections, the natural desiccation regime in the field might cause more photooxidative stress. In addition to increased VAZ pool size (Figure 3), the relative abundance of tocopherols increased with removal of UV from S. caninervis in the field (Figure 5 and Table 4), consistent with increased ROS activity. Tocopherols quench singlet oxygen from the PSII reaction center (Trebst, Depka \& HolländerCzytko 2002; Trebst 2003; Krieger-Liszkay 2005), and $\alpha$-tocopherol has been shown to confer antioxidant protection to thylakoid membranes in UV-B exposed spinach plants (Delong \& Steffen 1998). There are a number of stress protection mechanisms that are mediated by UVR8, the UV-B sensing protein receptor (Singh et al. 2014), many of which could result in slower $F_{\mathrm{v}} / F_{\mathrm{m}}$ recovery and increased antioxidant abundance with removal of UV. In fact, the UV-B response pathway and the photomorphogenesis pathway have substantial overlap (Stanley \& Yuan 2019).

\section{Laboratory UV treatment on field-treated samples}

In our study, application of an additional UV treatment to field-treated samples had no significant effect on $F$ ${ }_{\mathrm{v}} / F_{\mathrm{m}}$ of UV-reduced plants over the 192-hour simulated winter recovery period. This result suggests either that the one year of reduced UV in the field was not sufficient to remove previously acquired acclimation or that these plants may have a physiologically constitutive level of protection in this assay. However, the mechanism of protection in the UV-filtered and UV-transmitted plants might have been different, as there were differences in their pigment and antioxidant profiles. For example, zeaxanthin was higher in UV-filtered plants and zeaxanthin has been found to contribute to UV stress protection and UV damage prevention in tobacco plants (Götz et al. 2002). It is also possible that any PSII damage incurred by the UV treatment was repaired in the 30 minutes dark acclimation period prior to when the first fluorescence measurement was recorded. Curiously, UV-transmitted plants had significantly higher $F_{\mathrm{v}} / F_{\mathrm{m}}$ at $\mathrm{T}_{24}$ after the laboratory UV treatment, and UV-filtered plants showed the same pattern though it was not significant. This result lends further support to the hypothesis that UV exposure has beneficial effects on photosynthetic efficiency in $S$. caninervisas even a moderate dose of UV given to desiccated plants resulted in some improvement in $F$ v $/ F$ mrecovery.

\section{Conclusions}

In summary, we find evidence that Mojave Desert S. caninervisplants undergo a sustained form of NPQ that takes days to relax and for efficient photosynthesis to resume in simulated winter conditions. As these plants spend much of the summer season in a dry, quiescent state with no ability to photosynthesize or grow, it is reasonable to conclude that the observed changes $F_{\mathrm{v}} / F_{\mathrm{m}}$ suggest seasonal photoprotective thermal dissipation (Demmig-Adams, Cohu, Muller \& Adams 2012). Furthermore, reduction of UV radiation from natural sunlight had unexpected and adverse effects on recovery of photosynthetic efficiency in these plants. This counterintuitive result is consistent with effects from higher levels of singlet oxygen and other ROS, perhaps from high visible light in the absence of a UV regulatory signal to induce protective responses. Evidence to support this hypothesis includes significantly higher zeaxanthin, lutein, and tocopherols observed in UV-filtered plants - all potential antioxidants. Yet, all field-collected plants in this study had high levels of these antioxidants, which, along with the chlorophyll fluorescence results, suggests they undergo a strong and sustained form of NPQ, which in this system takes as long as eight days post-rehydration before highly efficient photosynthesis can resume. It is difficult to distinguish PSII damage due to ROS from sustained NPQ and it is possible that UV-reduced plants have higher NPQ. More research is needed to determine 
to what extent these two processes, ROS damage and sustained NPQ, are contributing to the observed altered recovery of $F_{\mathrm{v}} / F_{\mathrm{m}}$ in UV-reduced plants, and how these factors interact with desiccation in natural populations.

\section{Acknowledgements}

\section{Author Contribution}

JTBE, BDM, and TAC designed the research. JTBE performed field research. JTBE, OD, AR, TAC, and SE performed the laboratory research. JTBE and OD analyzed the data and all authors interpreted it. JTBE wrote the manuscript with support of all authors.

\section{References}

Agrawal S.B., Singh S. \& Agrawal M. (2009) Chapter 3: Ultraviolet-B Induced Changes in Gene Expression and Antioxidants in Plants.Advances in Botanical Research 52, 47-86.

Antoninka A., Bowker M.A., Reed S.C. \& Doherty K. (2016) Production of greenhouse-grown biocrust mosses and associated cyanobacteria to rehabilitate dryland soil function. Restoration Ecology 24 , 324-335.

Baroli I., Niyogi K.K., Barber J. \& Heifetz P. (2000) Molecular genetics of xanthophyll-dependent photoprotection in green algae and plants. Philosophical Transactions of the Royal Society B: Biological Sciences $355,1385-1394$.

Basahi J.M., Ismail I.M. \& Hassan I.A. (2014) Effects of enhanced UV-B radiation and drought stress on photosynthetic performance of lettuce (Lactuca sativa L. Romaine) plants. Annual Research $\mathcal{E}$ Review in Biology 4, 1739-1756.

Benjamini Y. \& Hochberg Y. (1995) Controlling the False Discovery Rate: A Practical and Powerful Approach to Multiple Testing. Journal of the Royal Statistical Society: Series B (Methodological) 57 , 289-300.

Björkman O. (1981) Responses to Different Quantum Flux Densities. InPhysiological Plant Ecology I , 12th ed. (eds O.L. Lange, P.S. Nobel, C.B. Osmond \& H. Ziegler), pp. 57-108. Springer-Verlag New York.

Björkman O. \& Demmig B. (1987) Photon yield of O2 evolution and chlorophyll fluorescence characteristics at $77 \mathrm{~K}$ among vascular plants of diverse origins. Planta $\mathbf{1 7 0}, 489-504$.

Björn L.O. (2007) Stratospheric ozone, ultraviolet radiation, and cryptogams. Biological Conservation 135 , 326-333.

Boelen P., De Boer M.K., De Bakker N.V.J. \& Rozema J. (2006) Outdoor studies on the effects of solar UV-B on bryophytes: Overview and methodology. Plant Ecology 182, 137-152.

Bowker M.A., Stark L.R., McLetchie D.N. \& Mishler B.D. (2000) Sex expression, skewed sex ratios, and microhabitat distribution in the dioecious desert moss Syntrichia caninervis (Pottiaceae).American Journal of Botany $87,517-526$.

Bradshaw A.D. (1965) Evolutionary significance of phenotypic plasticity in plants. Advances in Genetics 13 , $115-155$.

Van Buren R., Pardo J., Wai C.M., Evans S. \& Bartels D. (2019) Massive tandem proliferation of elips supports convergent evolution of desiccation tolerance across land plants. Plant Physiology 179 , 1040-1049.

Clark T.A. (2020) Can desert mosses hide from climate change? The ecophysiological importance of habitat buffering \& water relations to a keystone biocrust moss in the Mojave Desert. University of Nevada, Las Vegas. UNLV Retrospective Theses \& Dissertations.

Clarke L.J. \& Robinson S.A. (2008) Cell wall-bound ultraviolet-screening compounds explain the high ultraviolet tolerance of the Antarctic moss, Ceratodon purpureus . New Phytologist 179 , 776-783. 
Coe K.K., Belnap J. \& Sparks J.P. (2012) Precipitation-driven carbon balance controls survivorship of desert biocrust mosses. Ecology93, 1626-1636.

Cook R.D. (1977) Detection of influential observation in linear regression. Technometrics 19, 15-18.

Cooper-Driver G.A., Bhattacharya M. \& Harborne J.B. (1998) Role of phenolics in plant evolution. Phytochemistry 49 , 1165-1174.

Csintalan Z., Proctor M.C.F. \& Tuba Z. (1999) Chlorophyll fluorescence during drying and rehydration in the mosses Rhytidiadelphus loreus (Hedw.) Warnst., Anomodon viticulosus (Hedw.) Hook. and Tayl. and Grimmia pulvinata (Hedw.) Sm. Annals of Botany 84, 235-244.

Csintalan Z., Tuba Z., Takács Z. \& Laitat E. (2001) Responses of nine bryophyte and one lichen species from different microhabitats to elevated UV-B radiation. Photosynthetica 39 , 317-320.

Dautermann O., Lyska D., Andersen-Ranberg J., Becker M., Fröhlich-Nowoisky J., Gartmann H., ... Lohr M. (2020) An algal enzyme required for biosynthesis of the most abundant marine carotenoids. Science Advances 6 .

Davey M.P., Susanti N.I., Wargent J.J., Findlay J.E., Paul Quick W., Paul N.D. \& Jenkins G.I. (2012) The UV-B photoreceptor UVR8 promotes photosynthetic efficiency in Arabidopsis thaliana exposed to elevated levels of UV-B. Photosynthesis Research 114, 121-131.

Delong J.M. \& Steffen K.L. (1998) Lipid peroxidation and $\alpha$-tocopherol content in $\alpha$-tocopherol-supplemented thylakoid membranes during UV-B exposure. Environmental and Experimental Botany 39 , 177-185.

Demmig-Adams B. (1990) Carotenoids and photoprotection in plants: A role for the xanthophyll zeaxanthin. BBA - Bioenergetics1020, 1-24.

Demmig-Adams B., Cohu C.M., Muller O. \& Adams W.W. (2012) Modulation of photosynthetic energy conversion efficiency in nature: From seconds to seasons. Photosynthesis Research 113 , 75-88.

Demmig-Adams B. \& William W.A. (1996) Xanthophyll cycle and light stress in nature: Uniform response to excess direct sunlight among higher plant species. Planta 198 , 460-470.

Demmig B. \& Björkman O. (1987) Comparison of the effect of excessive light on chlorophyll fluorescence (77K) and photon yield of O2 evolution in leaves of higher plants. Planta 171, 171-184.

Dunn J.L. \& Robinson S.A. (2006) Ultraviolet B screening potential is higher in two cosmopolitan moss species than in a co-occurring Antarctic endemic moss: Implications of continuing ozone depletion. Global Change Biology 12, 2282-2296.

Ekwealor J.T.B. A suntan effect in the Mojave Desert moss Syntrichia caninervis. Mojave National Preserve E Sweeney Granite Mountains Desert Research Center: Science Newsletter .

Ekwealor J.T.B. \& Fisher K.M. (2020) Life under quartz: Hypolithic mosses in the Mojave Desert. PLOS ONE In Press.

Frohnmeyer H. \& Staiger D. (2003) Ultraviolet-B radiation-mediated responses in plants: Balancing damage and protection. Plant Physiology 113, 1420-1428.

Gaff D.F. (1977) Desiccation tolerant vascular plants of southern Africa. Oecologia 31 , 95-109.

Gitz D.C. \& Liu-Gitz L. (2003) How do UV photomorphogenic responses confer water stress tolerance? Photochemistry and Photobiology 78, 529-534.

Götz T., Sandmann G. \& Römer S. (2002) Expression of a bacterial carotene hydroxylase gene (crtZ) enhances UV tolerance in tobacco.Plant Molecular Biology 50 , 127-140.

Green T.G.A.A., Kulle D., Pannewitz S., Sancho L.G. \& Schroeter B. (2005) UV-A protection in mosses growing in continental Antarctica.Polar Biology 28, 822-827. 
Gwynn-Jones D., Lee J.A., Johanson U., Phoenix G.K., Callaghan T. V. \& Sonesson M. (1999) The response of plant functional types to enhanced UV-B radiation. In Stratospheric Ozone Depletion: the effects of enhanced UV-B radiation on terrestrial ecosystems . (ed J. Rozema), pp. 173-186. Swedish Polar Research Secretariat, Abisko Scientific Research Station.

He J., Huang L., Chow W., Whitecross M. \& Anderson J. (1993) Effects of supplementary ultraviolet-B radiation on rice and pea plants. Functional Plant Biology 20 , 129-142.

Hespanhol H., Fabón G., Monforte L., Martínez-Abaigar J. \& Núñez-Olivera E. (2014) Among- and withingenus variability of the UV-absorption capacity in saxicolous mosses. The Bryologist117 , 1-9.

Hoagland D.R. \& Arnon D.I. (1950) The water-culture method for growing plants without soil. Circular $34 \%$ California Agricultural Experiment Station 347, 32.

Horton P., Ruban A. V. \& Walters R.G. (1996) Regulation of light harvesting in green plants. Annual Review of Plant Physiology and Plant Molecular Biology 47, 655-684.

Hutin C., Nussaume L., Moise N., Moya I., Kloppstech K. \& Havaux M. (2003) Early light-induced proteins protect Arabidopsis from photooxidative stress. Proceedings of the National Academy of Sciences of the United States of America $100,4921-4926$.

Jafari M. \& Ansari-Pour N. (2019) Why, when and how to adjust your P values? Cell Journal 20 , 604-607.

Jahns P. \& Holzwarth A.R. (2012) The role of the xanthophyll cycle and of lutein in photoprotection of photosystem II. BBA - Bioenergetics 1817, 182-193.

Jahns P., Latowski D. \& Strzalka K. (2009) Mechanism and regulation of the violaxanthin cycle: The role of antenna proteins and membrane lipids. Biochimica et Biophysica Acta - Bioenergetics1787 , 3-14.

Jansen M.A.K., Gaba V. \& Greenberg B.M. (1998) Higher plants and UV-B radiation: Balancing damage, repair and acclimation. Trends in Plant Science 3, 131-135.

Jeffree C.E. (2007) The fine structure of the plant cuticle. InAnnual Plant Reviews: Biology of the Plant Cuticle . (eds M. Riederer \& C. Müller), Blackwell Publishing, Oxford, UK.

Kim C. \& Storer B.E. (1996) Reference values for cook's distance.Communications in Statistics Part B: Simulation and Computation 25, 691-708.

Krieger-Liszkay A. (2005) Singlet oxygen production in photosynthesis. Journal of Experimental Botany 56 , 337-346.

Lau T.S.L., Eno E., Goldstein G., Smith C. \& Christopher D.A. (2006) Ambient levels of UV-B in Hawaii combined with nutrient deficiency decrease photosynthesis in near-isogenic maize lines varying in leaf flavonoids: Flavonoids decrease photoinhibition in plants exposed to UV-B. Photosynthetica 44, 394-403.

Leong T.Y. \& Anderson J.M. (1984) Adaptation of the thylakoid membranes of pea chloroplasts to light intensities. I. Study on the distribution of chlorophyll-protein complexes. Photosynthesis Research5 , 105-115.

Li Z., Wakao S., Fischer B.B. \& Niyogi K.K. (2009) Sensing and responding to excess light. Annual Review of Plant Biology60 , 239-260.

Liguori N., Xu P., Van Stokkum I.H.M., Van Oort B., Lu Y., Karcher D., . . Croce R. (2017) Different carotenoid conformations have distinct functions in light-harvesting regulation in plants. Nature Communications 8, 1994 .

Lindahl M., Yang D. -H \& Andersson B. (1995) Regulatory proteolysis of the major light-harvesting chlorophyll a/b protein of photosystem II by a light-induced membrane-associated enzymic system. European Journal of Biochemistry 231, 503-509. 
Lud D., Moerdijk T.C.W., Van de Poll W.H., Buma A.G.J. \& Huiskes A.H.L. (2002) DNA damage and photosynthesis in Antarctic and ArcticSanionia uncinata (Hedw.) Loeske under ambient and enhanced levels of UV-B radiation. Plant, Cell and Environment 25 , 1579-1589.

Malnoe A. (2018) Photoinhibition or photoprotection of photosynthesis? Update on the (newly termed) sustained quenching component qH.Environmental and Experimental Botany 154, 123-133.

Mann H.B. \& Whitney D.R. (1947) On a Test of Whether one of Two Random Variables is Stochastically Larger than the Other. The Annals of Mathematical Statistics 18, 50-60.

Martinez-Abaigar J., Nunez-Olivera E., Beaucourt N., Garcia-Alvaro M.A., Tomas R. \& Arroniz M. (2003) Different physiological responses of two aquatic bryophytes to enhanced ultraviolet-B radiation. Journal of Bryology 25, 17-30.

Middleton E.M. \& Teramura A.H. (1993) The role of flavonol glycosides and carotenoids in protecting soybean from ultraviolet-B damage.Plant Physiology 103, 741-752.

Morales L.O., Brosche M., Vainonen J., Jenkins G.I., Wargent J.J., Sipari N., .. Aphalo P.J. (2013) Multiple roles for UV RESISTANCE LOCUS8 in regulating gene expression and metabolite accumulation in arabidopsis under solar ultraviolet radiation. Plant Physiology161, 744-759.

Muller P., Li X.P. \& Niyogi K.K. (2001) Non-photochemical quenching. A response to excess light energy. Plant Physiology .

Munne-Bosch S. (2005) The role of $\alpha$-tocopherol in plant stress tolerance. Journal of Plant Physiology 162 , $743-748$.

Murchie E.H. \& Lawson T. (2013) Chlorophyll fluorescence analysis: A guide to good practice and understanding some new applications. Journal of Experimental Botany 64, 3983-3998.

Newsham K.K. (2003) UV-B radiation arising from stratospheric ozone depletion influences the pigmentation of the Antarctic moss Andreaea regularis . Oecologia 135 , 327-331.

Niyogi K.K. (2000) Safety valves for photosynthesis. Current Opinion in Plant Biology 3 , 455-460.

Núñez-Olivera E., Arróniz-Crespo M., Martínez-Abaigar J., Tomás R. \& Beaucourt N. (2005) Assessing the UV-B tolerance of sun and shade samples of two aquatic bryophytes using short-term tests. The Bryologist $108,435-448$.

Oliver M.J., Dowd S.E., Zaragoza J., Mauget S.A. \& Payton P.R. (2004) The rehydration transcriptome of the desiccation-tolerant bryophyte Tortula ruralis: Transcript classification and analysis. BMC Genomics $\mathbf{5}$

Poulson M.E., Boeger M.R.T. \& Donahue R.A. (2006) Response of photosynthesis to high light and drought for Arabidopsis thaliana grown under a UV-B enhanced light regime. Photosynthesis Research 90 , 79-90.

Proctor M. (2001) Patterns of desiccation tolerance and recovery in bryophytes. Plant Growth Regulation $35,147-156$.

Proctor M.C.F., Oliver M.J., Wood A.J., Alpert P., Stark L.R., Cleavitt N.L. \& Mishler B.D. (2007) Desiccation-tolerance in bryophytes: a review. The Bryologist 110 , 595-621.

Pukacki P.M. \& Modrzyński J. (1998) The influence of ultraviolet-B radiation on the growth, pigment production and chlorophyll fluorescence of Norway spruce seedlings. Acta Physiologiae Plantarum 20 , 245250.

Ranjbarfordoei A., Samson R. \& Van Damme P. (2011) Photosynthesis performance in sweet almond Prunus dulcis (Mill) D. Webb] exposed to supplemental UV-B radiation. Photosynthetica 49 , 107-111. 
Ritchie G.A. (2006) Chlorophyll Fluorescence: What is it and what do the numbers mean? In USDA Forest Service Proceedings RMRS-P-43 . pp. 34-43.

Robinson S.A., Turnbull J.D. \& Lovelock C.E. (2005) Impact of changes in natural ultraviolet radiation on pigment composition, physiological and morphological characteristics of the Antarctic moss, Grimmia antarctici. Global Change Biology 11, 476-489.

Robson T.M., Hartikainen S.M. \& Aphalo P.J. (2015) How does solar ultraviolet-B radiation improve drought tolerance of silver birch (Betula pendula Roth.) seedlings? Plant, Cell and Environment38 , 953-967.

Rozema J., Van De Staaij J., Björn L.O. \& Caldwell M. (1997) UV-B as an environmental factor in plant life: Stress and regulation. Trends in Ecology and Evolution 12, 22-28.

Ruban A. V. (2016) Nonphotochemical chlorophyll fluorescence quenching: Mechanism and effectiveness in protecting plants from photodamage. Plant Physiology 170 , 1903-1916.

Searles P.S., Flint S.D. \& Caldwell M.M. (2001) A meta-analysis of plant field studies simulating stratospheric ozone depletion. Oecologia $127,1-10$.

Searles P.S., Flint S.D., Díaz S.B., Rousseaux M.C., Ballaré C.L. \& Caldwell M.M. (1999) Solar ultraviolet$B$ radiation influence on Sphagnum bog and Carex fen ecosystems: First field season findings in Tierra del Fuego, Argentina. Global Change Biology 5 , 225-234.

Seppelt R.D., Downing A.J., Deane-Coe K.K., Zhang Y. \& Zhang J. (2016) Bryophytes within biological soil crusts. In Biological Soil Crusts: An Organizing Principle in Drylands, Ecological Studies 226, Ecological. (eds B. Weber, B. Büdel \& J. Belnap), pp. 101-120.

Shapiro S.S. \& Wilk M.B. (1965) An analysis of variance test for normality (complete samples). Biometrika $\mathbf{5 2}, 591-611$.

Siefermann-Harms D. (1985) Carotenoids in photosynthesis. I. Location in photosynthetic membranes and light-harvesting function. BBA Reviews On Bioenergetics 811, 325-355.

Singh S., Agrawal S.B. \& Agrawal M. (2014) UVR8 mediated plant protective responses under low UV-B radiation leading to photosynthetic acclimation. Journal of Photochemistry and Photobiology B: Biology 137 , $67-76$.

Stanley L. \& Yuan Y.W. (2019) Transcriptional regulation of carotenoid biosynthesis in plants: So many regulators, so little consensus. Frontiers in Plant Science 10 .

Stark L.R. (2005) Phenology of patch hydration, patch temperature and sexual reproductive output over a four-year period in the desert moss Crossidium crassinerve. Journal of Bryology 27, 231-240.

Stark L.R. (2017) Ecology of desiccation tolerance in bryophytes: A conceptual framework and methodology. The Bryologist120 , 130-165.

Stark L.R., Mishler B.D. \& McLetchie D.N. (1998) Sex expression and growth rates in natural populations of the desert soil crustal mossSyntrichia caninervis . Journal of Arid Environments40 , 401-416.

Strid A., Chow W.S. \& Anderson J.M. (1990) Effects of supplementary ultraviolet-B radiation on photosynthesis in Pisum sativum. BBA - Bioenergetics 1020 , 260-268.

Sun T., Yuan H., Cao H., Yazdani M., Tadmor Y. \& Li L. (2018) Carotenoid metabolism in plants: The role of plastids. Molecular Plant 11, 58-74.

Takács Z., Csintalan Z., Sass L., Laitat E., Vass I. \& Tuba Z. (1999) UV-B tolerance of bryophyte species with different degrees of desiccation tolerance. Journal of Photochemistry and Photobiology B: Biology 48 , $210-215$. 
Teramura A.H. \& Sullivan J.H. (1994) Effects of UV-B radiation on photosynthesis and growth of terrestrial plants. Photosynthesis Research 39 , 463-473.

Trebst A. (2003) Function of $\beta$-carotene and tocopherol in Photosystem II. Zeitschrift fur Naturforschung Section C Journal of Biosciences .

Trebst A., Depka B. \& Holländer-Czytko H. (2002) A specific role for tocopherol and of chemical singlet oxygen quenchers in the maintenance of photosystem II structure and function in Chlamydomonas reinhardtii.FEBS Letters $\mathbf{5 1 6}, 156-160$.

Turnbull J.D., Leslie S.J. \& Robinson S.A. (2009) Desiccation protects two Antarctic mosses from ultravioletB induced DNA damage. Functional Plant Biology 36, 214-221.

Ulm R. \& Nagy F. (2005) Signalling and gene regulation in response to ultraviolet light. Current Opinion in Plant Biology $8,477-482$.

Verhoeven A.S., Adams W.W. \& Demmig-Adams B. (1996) Close relationship between the state of the xanthophyll cycle pigments and photosystem II efficiency during recovery from winter stress. Physiologia Plantarum $96,567-576$.

Waterman M.J., Nugraha A.S., Hendra R., Ball G.E., Robinson S.A. \& Keller P.A. (2017) Antarctic moss biflavonoids show high antioxidant and ultraviolet-screening activity. Journal of Natural Products $\mathbf{8 0}, 2224-$ 2231 .

Wilcoxon F. (1945) Individual comparisons by ranking methods.Biometrics Bulletin 1, 80-83.

Wolf L., Rizzini L., Stracke R., Ulm R. \& Rensing S.A. (2010) The molecular and physiological responses of Physcomitrella patens to ultraviolet-B radiation. Plant Physiology 153 , 1123-1134.

Yamakawa H., Fukushima Y., Itoh S. \& Heber U. (2012) Three different mechanisms of energy dissipation of a desiccation-tolerant moss serve one common purpose: To protect reaction centres against photooxidation. Journal of Experimental Botany 63, 3765-3775.

Yamakawa H. \& Itoh S. (2013) Dissipation of excess excitation energy by drought-induced nonphotochemical quenching in two species of drought-tolerant moss: Desiccation-induced acceleration of Photosystem II fluorescence decay. Biochemistry 52, 4451-4459.

Yamamoto H.Y., Bugos R.C. \& David Hieber A. (2006) Biochemistry and Molecular Biology of the Xanthophyll Cycle. In The Photochemistry of Carotenoids .

Yao Y., You J., Ou Y., Ma J., Wu X. \& Xu G. (2015) Ultraviolet-B protection of ascorbate and tocopherol in plants related with their function on the stability on carotenoid and phenylpropanoid compounds.Plant Physiology and Biochemistry $90,23-31$.

Zeng Q. (2002) Two early light-inducible protein (ELIP) cDNAs from the resurrection plant Tortula ruralis are differentially expressed in response to desiccation, rehydration, salinity, and high light.Journal of Experimental Botany 53, 1197-1205.

Zotz G. \& Kahler H. (2007) A moss "canopy" - Small-scale differences in microclimate and physiological traits in Tortula ruralis .Flora 202, 661-666.

\section{Figures}

Figure 1 Natural Syntrichia caninervis. (a) Experimental setup, showing UV-filtering and UV-transmitting windows over S. caninervis cushions in the Mojave Desert. (b) Desiccated S. caninervis shoots.

Figure 2 Maximum potential Photosystem II quantum efficiency of UV-filtered, UV-transmitted, and site reference Syntrichia caninervis over a simulated winter recovery period. $F_{\mathrm{v}} / F_{\mathrm{m}}$ at each time point were compared pairwise using Wilcoxon signed-rank tests and adjusted for multiple-testing with the Benjamini and Hochberg method. ${ }^{*}=P<0.05,{ }^{* *}=P<0.01,{ }^{* * *}=P<0.001,{ }^{* * * *}=P<0.0001$. 
Figure 3 Relative content of photosynthetic pigments in UV-filtered, UV-transmitted, and site reference Syntrichia caninervis. Pigment and antioxidant content were quantified by HPLC in at least triplicate and normalized to total pigment content. Means were compared across field treatments using Wilcoxon signedrank tests with the Benjamini and Hochberg correction for multiple tests. ${ }^{*}=P<0.05,{ }^{* *}=P<0.01,{ }^{* * *}$ $=P<0.001,{ }^{* * * *}=P<0.0001$.

Figure 4 Principle components biplot of 1st and 2nd PCA scores based on relative photosynthesis pigment and tocopherol content in UV-filtered, UV-transmitted, un-altered field-collected (site reference), and laboratory cultured Syntrichia caninervis.Vectors are overlaid and scaled to show the strength of correlation. Composition $68 \%$ probability ellipses show the means (ellipse centers) and variation by treatment. Pigment and antioxidant content were quantified by HPLC in at least triplicate and normalized to total pigment content. Replicates were screened for outliers.

Figure 5 Relative tocopherol content in UV-filtered, UV-transmitted, and un-altered site reference Syntrichia caninervis.

Tocopherol content was quantified by HPLC in at least triplicate and normalized to total chlorophyll content. Means were compared across field treatments using Wilcoxon signed-rank tests with the Benjamini and Hochberg correction for multiple tests. ${ }^{*}=P<0.05,{ }^{* *}=P<0.01,{ }^{* * *}=P<0.001,{ }^{* * * *}=P<0.0001$.

Table 1 Microclimate in UV-filtered and UV-transmitted Mojave Desert microsites.

Winter

Summer

Mean \pm standard deviation. Adjusted P-values reported for an ANOVA with Benjamini \& Hochberg correction; $\mathrm{n}=$ numbe

Table 2 Mean quantum efficiency of Photosystem II ( PPSII) in UV-filtered and UV-transmitted Syntrichia caninervis plants over a simulated winter recovery period.

Time in recovery (hours)

0

24

192

Adjusted P-values reported for Wilcoxon signed-rank tests with Benjamini \& Hochberg correction. Mean \pm standard devia

Table 3 Mean relative abundance of photosynthesis pigments in field-collected and laboratory cultured Syntrichia caninervisplants.

\begin{tabular}{lllll}
\hline & $\begin{array}{l}\text { Field-collected }(\% \\
\text { of total pigment) }\end{array}$ & $\begin{array}{l}\text { Lab-cultured }(\% \text { of } \\
\text { total pigment })\end{array}$ & $\mathrm{n}_{\mathrm{F}}, \mathrm{n}_{\mathrm{L}}$ & P-value \\
\hline Violaxanthin & $0.589 \pm 0.118$ & $3.72 \pm 0.701$ & 54,9 & $<0.0001$ \\
Antheraxanthin & $1.43 \pm 0.193$ & $1.29 \pm 0.269$ & 54,9 & $\mathrm{~ns}$ \\
Zeaxanthin & $7.54 \pm 1.08$ & $1.30 \pm 0.279$ & 54,9 & $<0.0001$
\end{tabular}




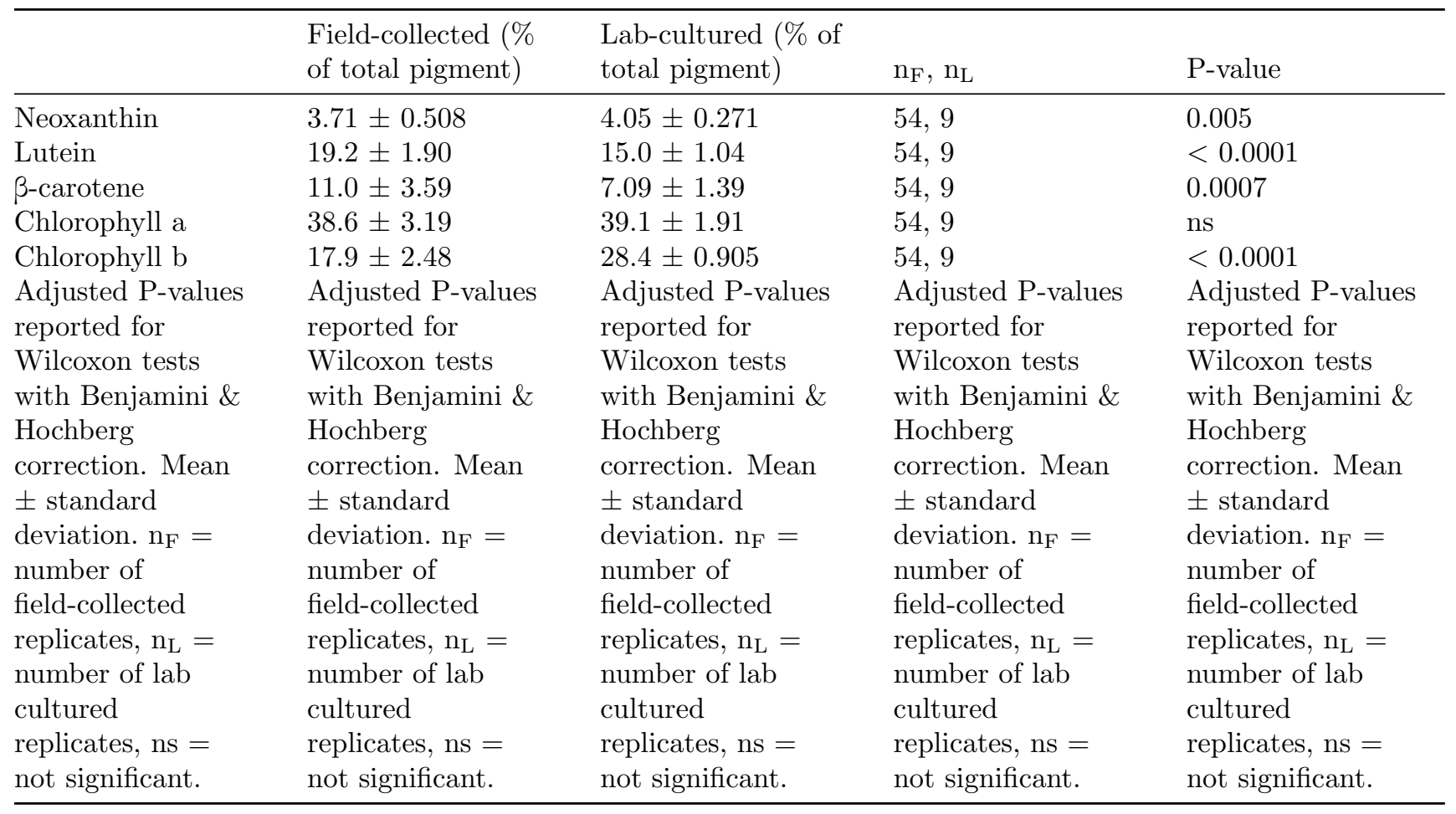

Table 4 Mean relative abundance of tocopherols in UV-filtered, UV-transmitted, and site reference control Syntrichia caninervisplants.

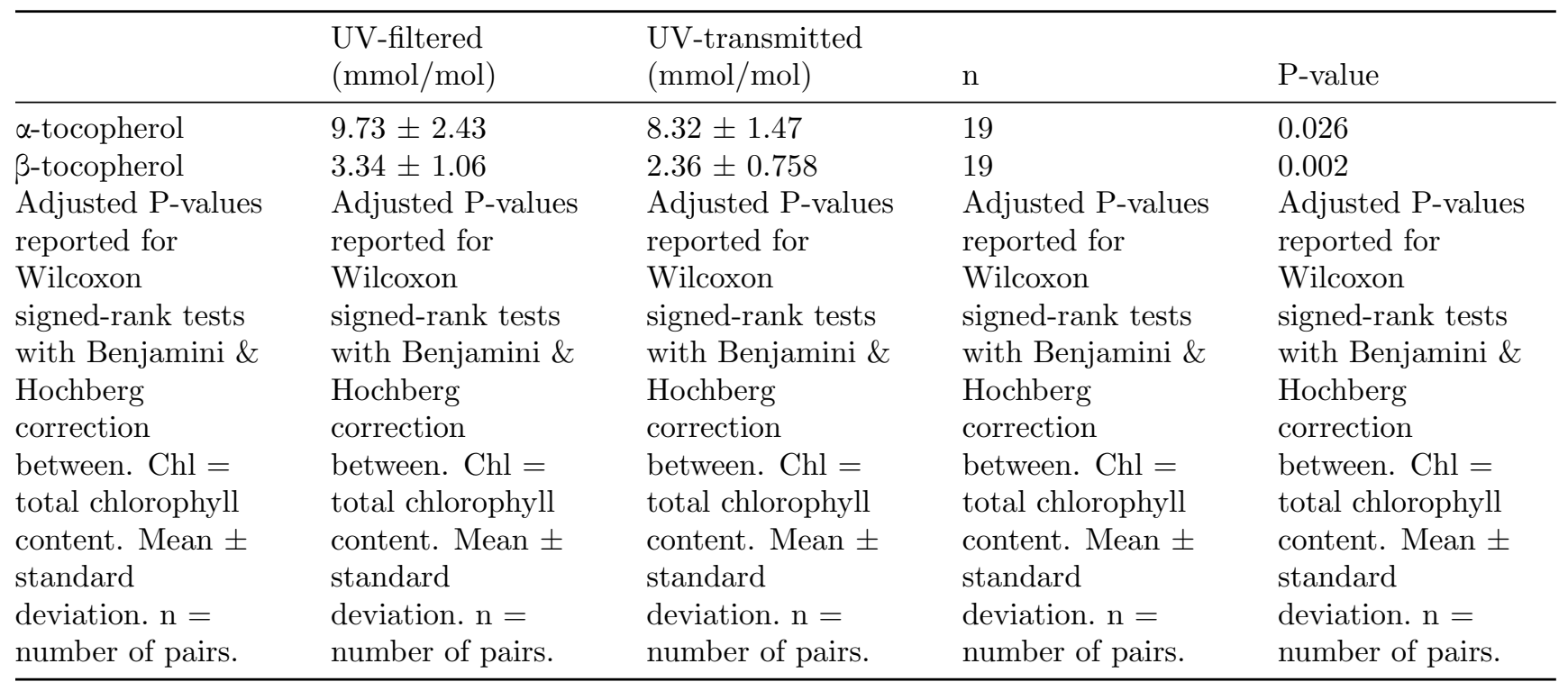

Table 5 Mean relative abundance of tocopherols in field-collected and laboratory cultured Syntrichia caninervisplants. 


\begin{tabular}{lllll}
\hline & $\begin{array}{l}\text { Field-collected } \\
(\mathrm{mmol} / \mathrm{mol})\end{array}$ & $\begin{array}{l}\text { Lab-cultured } \\
(\mathrm{mmol} / \mathrm{mol})\end{array}$ & $\mathrm{n}_{\mathrm{F}}, \mathrm{n}_{\mathrm{L}}$ & P-value \\
\hline$\alpha$-tocopherol & $12.8 \pm 3.95$ & $5.08 \pm 1.61$ & 54,9 & $<0.0001$ \\
$\beta$-tocopherol & $3.74 \pm 1.36$ & $0.678 \pm 0.405$ & 54,9 & $<0.0001$ \\
Adjusted P-values & Adjusted P-values & $\begin{array}{l}\text { Adjusted P-values } \\
\text { reported for }\end{array}$ & $\begin{array}{l}\text { Adjusted P-values } \\
\text { reported for }\end{array}$ & $\begin{array}{l}\text { Adjusted P-values } \\
\text { reported for }\end{array}$ \\
reported for & reported for & Wilcoxon tests & Wilcoxon tests & Wilcoxon tests \\
Wilcoxon tests & Wilcoxon tests & with & with Benjamini \& \\
with Benjamini \& & with Benjamini \& & with Benjamini \& & with Benjamini \& & with \\
Hochberg & Hochberg & Hochberg & Hochberg & Hochberg \\
correction. Chl $=$ & correction. Chl $=$ & correction. Chl $=$ & correction. Chl $=$ & correction. Chl $=$ \\
total chlorophyll & total chlorophyll & total chlorophyll & total chlorophyll & total chlorophyll \\
content. Mean \pm & content. Mean \pm & content. Mean \pm & content. Mean \pm & content. Mean \pm \\
standard & standard & standard & standard & standard \\
deviation. $\mathrm{n}_{\mathrm{F}}=$ & deviation. $\mathrm{n}_{\mathrm{F}}=$ & deviation. $\mathrm{n}_{\mathrm{F}}=$ & deviation. $\mathrm{n}_{\mathrm{F}}=$ & deviation. $\mathrm{n}_{\mathrm{F}}=$ \\
number of & number of & number of & number of & number of \\
field-collected & field-collected & field-collected & field-collected & field-collected \\
replicates, $\mathrm{n}_{\mathrm{L}}=$ & replicates, $\mathrm{n}_{\mathrm{L}}=$ & replicates, $\mathrm{n}_{\mathrm{L}}=$ & replicates, $\mathrm{n}_{\mathrm{L}}=$ & replicates, $\mathrm{n}_{\mathrm{L}}=$ \\
number of lab & number of lab & number of lab & number of lab & number of lab \\
cultured & cultured & cultured & cultured & cultured \\
replicates. & replicates. & replicates. & replicates. & replicates. \\
\hline
\end{tabular}

\section{Hosted file}

Figure1.pdf available at https://authorea.com/users/342727/articles/469562-uv-tolerance-andsustained-non-photochemical-quenching-in-a-desert-moss

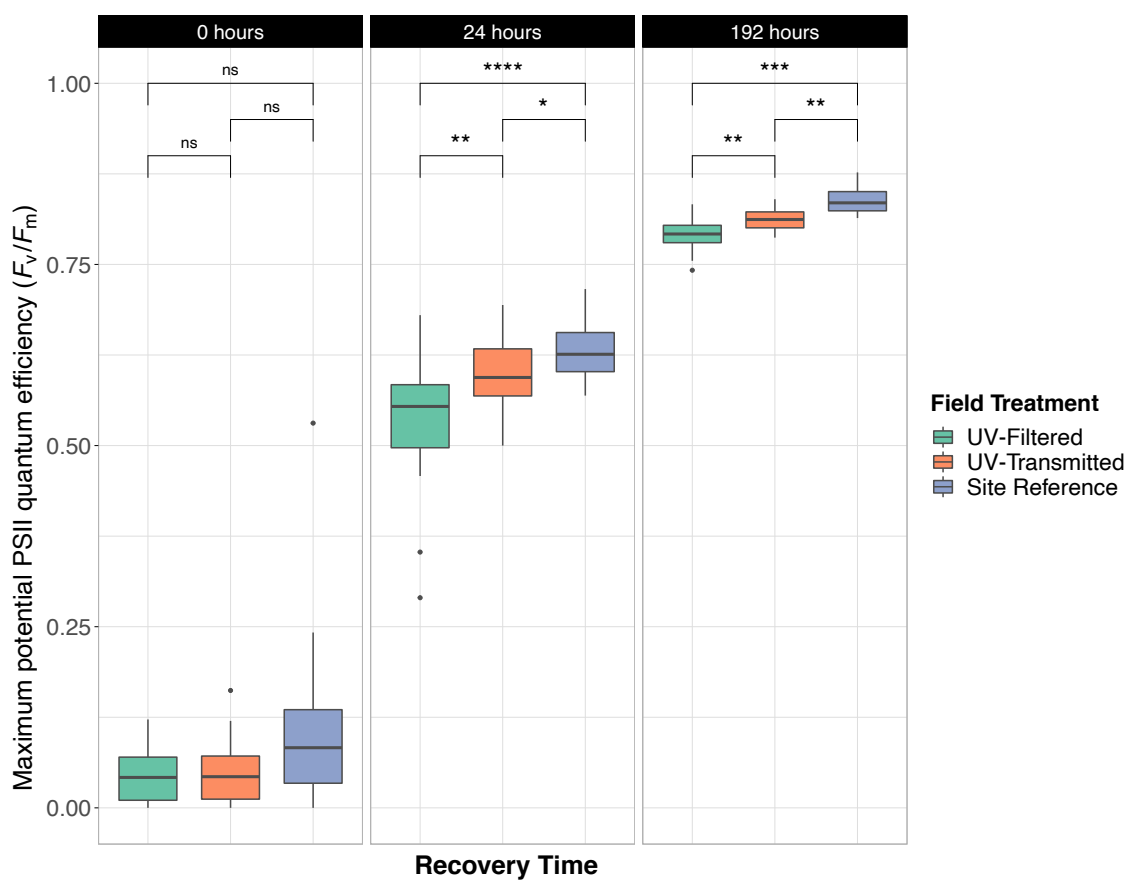




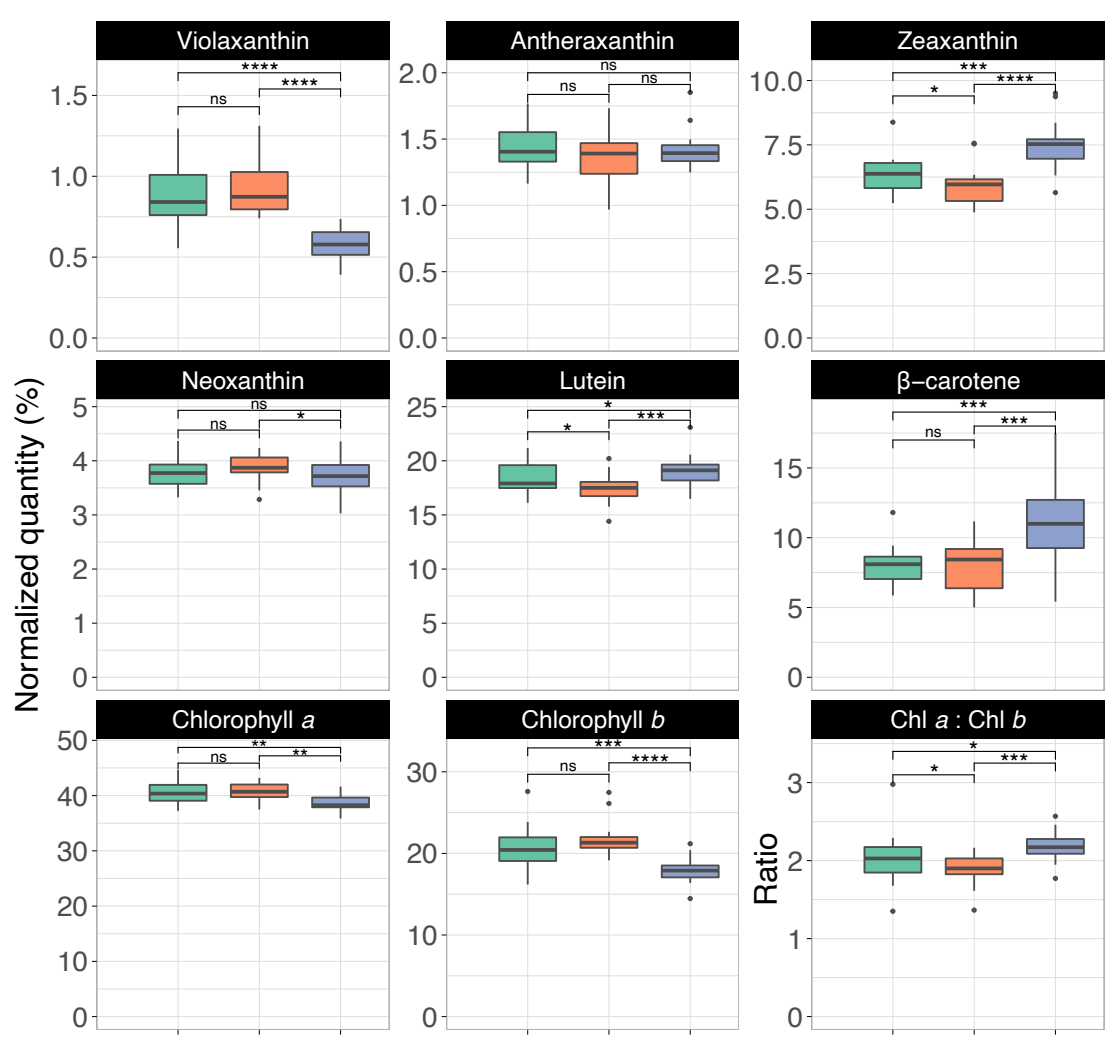

Field Treatment

官 UV-Filtered 追 UV-Transmitted 追 Site Reference

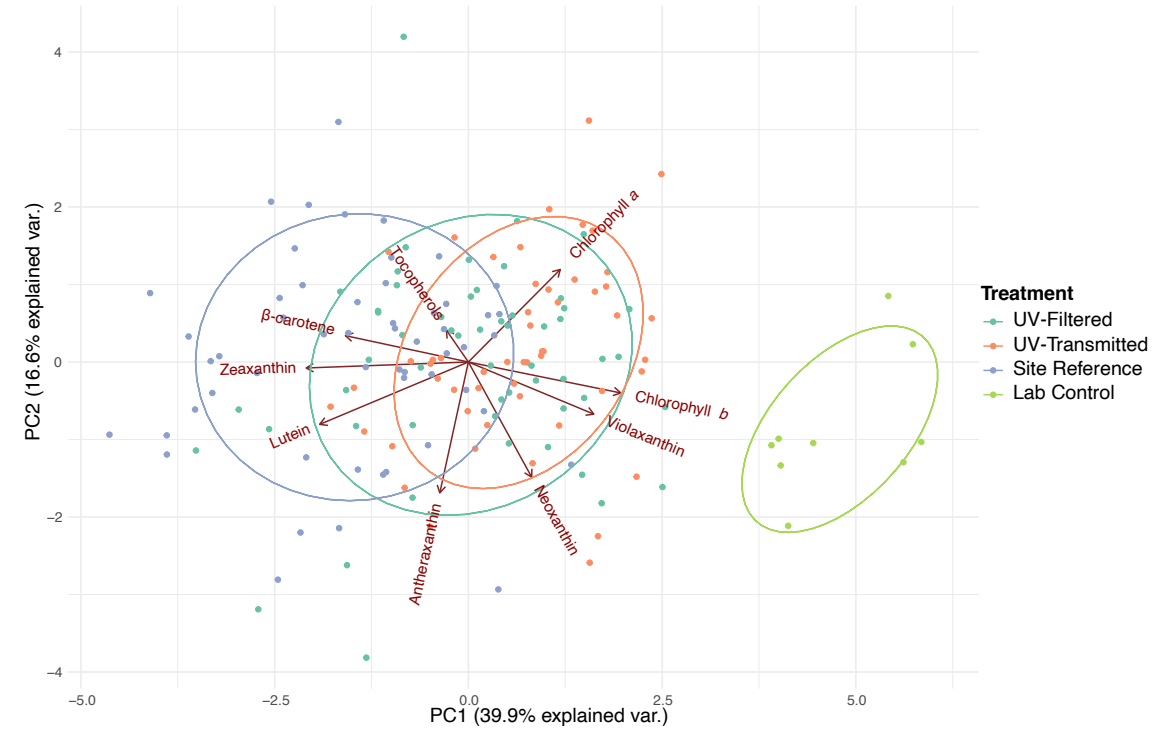




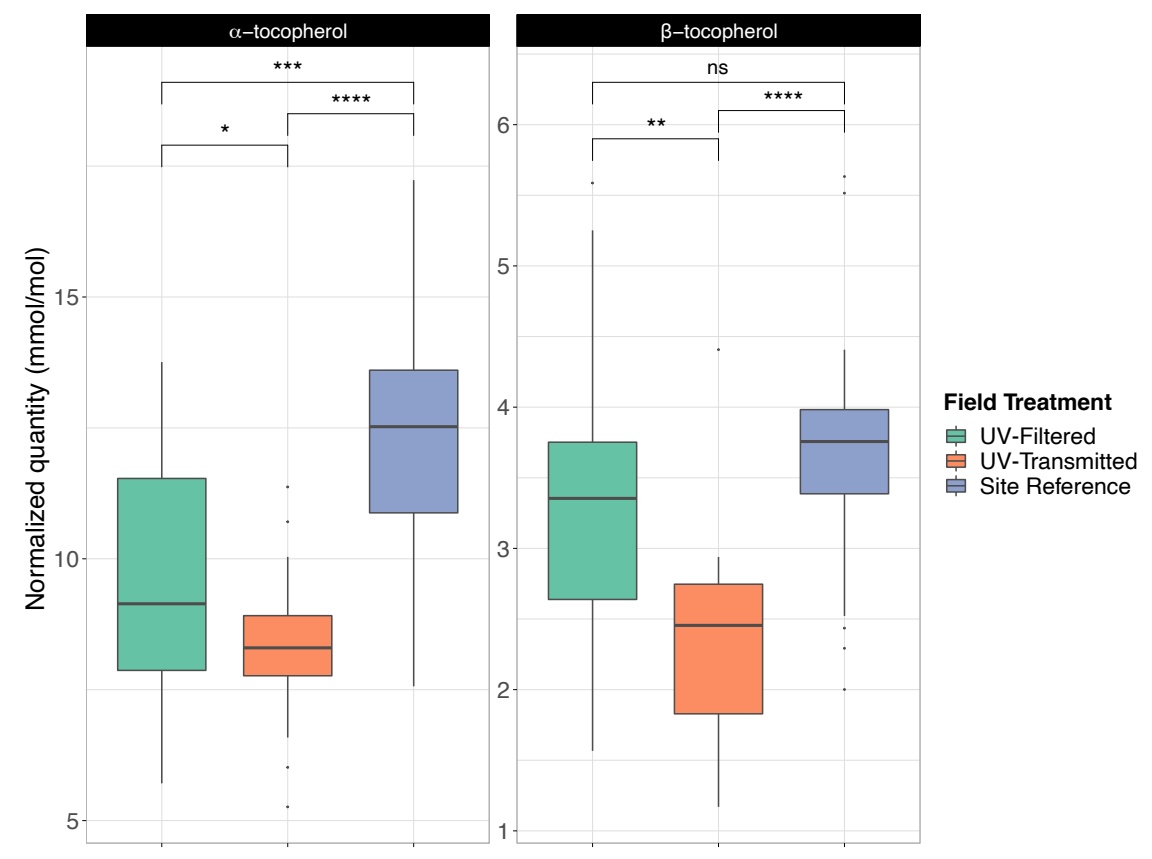

